https://helda.helsinki.fi

\title{
Resilience and Vulnerability of Northern Regions to Social and Environmental Change
}

Chapin, F.S.

Royal Swedish Academy of Sciences

2004

Chapin, F.S. et al. 2004. Resilience and Vulnerability of Northern Regions to Social and Environmental Change. Ambio 33(6): 344-349.

http://hdl.handle.net/1975/253

Downloaded from Helda, University of Helsinki institutional repository.

This is an electronic reprint of the original article.

This reprint may differ from the original in pagination and typographic detail.

Please cite the original version. 


\section{Resilience and Vulnerability of Northern Regions to Social and Environmental Change}

The arctic tundra and boreal forest were once considered the last frontiers on earth because of their vast expanses remote from agricultural land-use change and industrial development. These regions are now, however, experiencing environmental and social changes that are as rapid as those occurring anywhere on earth. This paper summarizes the role of northern regions in the global system and provides a blueprint for assessing the factors that govern their sensitivity to social and environmental change.

\section{ROLE OF ARCTIC TUNDRA AND BOREAL FOREST IN} THE GLOBAL SYSTEM

Arctic tundra and boreal forest occupy $15 \%$ of the ice-free terrestrial surface, an area larger than either tropical or temperate forests (1). These northern biomes play a key role in the global climate system. particularly during times of climatic change. The global warming trend of the past century (2) is amplified at high latitudes. because sea ice and snowmelt occur more extensively and earlier in the spring, converting white reflective surfaces to darker vegetation and water, which absorb more solar energy and transfer it to the atmosphere (3). Northward expansion of forests or increases in shrubs within tundra that occur in response to regional warming cause further increases in the absorption of energy and its transfer to the atmosphere (4. 5). Temperatures are now increasing in northern high latitudes more rapidly than at any time in the last 400 years (6).

ligh-latitude warming can trigger changes that exert pronounced effects on the global climate system. Arctic and boreal ecosystems store a third of earth's soil carbon (7) as a result of cold and/or anaerobic soil conditions that constrain decomposition. This is equivalent to two-thirds of the carbon content of the atmosphere. If high-latitude warming enhances carbon loss through decomposition or wildfire to a greater extent than carbon gain from plant production, some of this large carbon store would be released to the atmosphere and amplify the $\mathrm{CO}_{2}$-induced warming of global climate $(8)$, but there is high uncertainty of these potential changes (9). and they could be reduced or reversed by appropriate policies.

Other potential changes in high-latitude feedbacks to the global climate system are more speculative but potentially important. Hydrologic changes that occur when permafrost (permanently frozen ground) thaws may increase the flux of methane in lowlands or decrease fluxes in uplands. Northern ecosystems are a large and increasing source of methane (10), a greenhouse gas 20 -fold more potent than $\mathrm{CO}_{2}$ in its potential to warm the atmosphere. Finally, discharge of rivers that drain from tundra and boreal forest into the Arctic Ocean has increased $7 \%$ in the last 70 years (11), a trend that, if continued, could destabilize thermohaline circulation and the global heat transport through the oceans by the end of the $21^{\text {st }}$ century.

The north is increasingly linked to the global economy by new modes of transportation and communication. If the North- ern Sea Route above Eurasia or the Northwest Passage above North America becomes ice-free during summer, as expected within the present century, these connections will become even stronger. An ice-free Arctic Ocean might. for example, make the extraction of oil and gas from northern regions more economical. These are the largest proven oil and gas reserves in the world, but their extraction is currently too costly to compete effectively on the global market.

Arctic and boreal regions are home to numerous native cultures, most of which still have strong cultural ties to the land and/or seas. The traditional knowledge that has been the basis of their survival is a rich source of experience in the management of natural resources. At a time when many of the world's fisheries, forests, and other renewable resources are threatened by overexploitation, these diverse cultural traditions may provide sources of innovation that could lead to more sustainable strategies of resource management in the north (12.13). However, the natural biological resources in the north are threatened by anthropogenic impacts from outside the region, such as climate change. Species like mosses, lichens, and algae, which are well represented in the north. often play important roles as "ecosystem engineers" by creating soil organic matter. insulating sub-surface ground temperatures and permafrost. and sequestering nutrients. Such species are particularly sensitive to changes in the environment and disturbance regime.

In summary, northern ecosystems are increasingly linked to the rest of the globe through myriad physical, biological. cultural, and economic ties. Our challenge is to recognize and promote those attributes of linked social-ecological systems that will reduce their sensitivity to the onslaught of rapid global change.

\section{RESILIENCE AS A FRAMEWORK FOR ASSESSING RESPONSES TO GLOBAL CHANGE}

Efforts to rigidly maintain the current properties of northern systems in the face of multiple interacting global changes are doomed to failure. These properties are a product of the history of these systems and their current physical and social environments. As these environments change, so will the specific attributes of the system. For example, as climate warms, the relative abundance of species changes (14). areas of human disturbance become more vulnerable to invasion by exotic species (15), and the retreat of sea ice reduces opportunities for coastal indigenous communities to bunt for ice-dependent marine mammals (16). We suggest that managing for ecosystem and landscape resilience rather than for specific properties, such as the abundance of a particular species, has greater potential to sustain those fundamental features of northern systems that are most important to society. In this section we define and outline a strategy for enhancing regional resilience.

The first step in managing for resilience is to recognize that people and their institutions are integral components of ecological systems. Consequently. regions must be treated as 
linked social-ecological systems rather than simply as human societies that derive services such as clean water and air, food, and fuel from the ecosystems that they inhabit (17). In this context. resilience is the magnitude of disturbance that can be absorbed by a system without fundamentally changing it (18). "More resilient systems are able to absorb larger shocks. When massive transformations occur, resilient systems contain the components needed for renewal and reorganization. In other words. they can cope, adapt, or reorganize without sacrificing the provision of ecosystem services. Resilience is often associated with diversity of species, of human opportunity, and of economic options, that maintains and encourages both adaptation and learning. In general, resilience derives from things that can be restored only slowly, such as reservoirs of soil nutrients. heterogeneity of ecosystems on a landscape, or variety of genotypes and species" $(19,20)$. In contrast, systems can be sensitive to rapid changes in either the environment or the disturbance regime. The outcome, or vulnerability of the system. is the balance between the accumulated resilience and the shorter-term sensitivity.

Social-ecological systems are always changing. Managers often seek to control these changes, for example to maintain fish or forest stocks at constant levels, and to reduce biological variability by selecting useful plants/crops/trees and removing/reducing competitors, pests and pathogens. These efforts frequently fail to appreciate the importance of variability and diversity as essential components of regional systems. Management that seeks to prevent change or reduce variability often leads to collapse rather than to maintenance of the system. In contrast, management aimed at building resilience depends on active adaptive management built on flexibility and learning $(21)$. It focuses on slowly changing variables that create memory, legacy, diversity and the capacity to innovate in both social and ecological components of the system. By nurturing those diverse elements that are necessary to reorganize and adapt to novel circumstances, it increases the range of surprises with which the system can cope (19).

\section{SOURCES OF RESILIENCE AND VULNERABILITY IN NORTHERN SYSTEMS}

What attributes of northern systems predispose them to resilience or make them vulnerable to change? What more must we learn to assess the vulnerability of northern regions to global changes? Once these attributes are identified, we have the foundation for developing policies that enhance regional resilience.

\section{Diversity}

Diversity has important ecological, cultural, and economic dimensions. Species diversity of most major groups of organisms declines with increasing latitude and therefore is lower in the arctic and boreal forest than in most major biomes on earth $(9$. 22). Many important northern species have broad circumpolar distributions. Extensive areas of forest are often dominated by a single tree species, such as Picea mariana (black spruce) in North America or Larix siberica (larch) in Siberia. Environmental or biotic changes that radically change the abundances of these species could cause widespread changes that cascade through all components of the social-ecological system (23). For example, an outbreak of Siberian silk moth (Dendrolimus sibiricus superans) and subsequent wood-boring insects in the mid 1990s destroyed about 1.5 million ha of productive forests and dramatically impacted life over a large region of Central Siberia (24) (Shvidenko. pers. comm.). We know less about the genetic diversity that might reduce vulnerability of these widespread species to change.

In contrast to the low species diversity, northern ecosystems exhibit a high degree of landscape diversity due to the low sun angle and presence of permafrost, which create radically different local microenvironments and the pervasiveness of natural disturbances such as fire and insect outbreaks that affect large areas (25). In topographically diverse areas, this landscape diversity gives rise to a wide range of microclimates. ecosystem types, and successional stages within a small arca, providing a wide range of local environmental adaptations that enhance the resilience of northern systems to climatic change.

There is also a rich diversity of cultural heritages. both western and indigenous. Northern regions are unusual in still having a land-based economy and large per capita harvests of marine mammals, fish, and wildlife. These cultures provide a diversity of resource management systems that have withstood the test of time. For example, traditional management practices often take advantage of landscape diversity through rotational use of areas (rotating fishing lakes and rivers; rotating beaver trapping areas). The cultural diversity in resource management traditions is a largely untapped source of resilience that can be integrated with western science to provide opportunities for novel approaches to monitoring and management of natural resources $(12,26)$.

In contrast to the richness of traditional resource management systems, a major source of vulnerability is the low diversity of 'modern' economic options that have been developed in most northern countries. Often the economy of a region is dominated by a single extractive industry such as oil and gas. hydropower, mining. or forestry. These industries provide little value-added multiplier to the local economy and make these regions vulnerable to changes in global demand for these resources (27). Enhancing local economic diversification is a critical step toward increasing the resilience of northern regions.

\section{Response to Temporal Variability and Change}

Most arctic and boreal organisms are well adapted to withstand large annual temperature changes $\left(+30^{\circ}\right.$ to $\left.-60^{\circ} \mathrm{C}\right)$ and are therefore quite resilient to the direct effects of temperature change (28). Low temperatures exclude invasion by most exotic species (29). As this thermal filter becomes relaxed by high-latitude warming, invasions may occur more frequently; especially in anthropogenic disturbances, where there are rclatively large inputs of exotic seeds, and competition from native vegetation is reduced (15). Temperature exerts important indirect effects on arctic organisms and ecosystems through changes in permafrost and soil moisture. Even small changes in summer temperature, for example. can shift individual forest stands from being a net carbon sink to a source (30). Changes in natural disturbances associated with changing weather patterns can have the same effect at continental scales (31, 32). Changes in direct annual emissions from wild fires in Canada. for example, can be of the same order of magnitude as lossil fuel emissions in that country (33).

In most northern countries, indigenous cultures have often been subject to intensive assimilation programs. yet many have proven their resilience and retain much of their cultural heritage and their close relationship to terrestrial, aquatic and marine ecosystems. However, changes from nomadic to sedentary lifestyles, e.g. Saami and Nenets herders. moving of children to distant schools for education, economic infusions into coastal fishing communities from North Sea oil development, migration to cities, and numerous other changes have gradually 
eroded both cultural traditions and the sense of self-sufficiency that make these traditions meaningful. The mixed economies that now characterize most of these communities provide both opportunities for innovation, e.g. purchase of snow machines to support subsistence activities and new sets of values that often compete with traditional values.

Most northern countries experience a boom-and-bust economy associated with mineral and petroleum discoveries and changes in global markets. This high economic vulnerability is ty pical of regions where the economy is dominated by extractive industries. The motivation for governments to encourage extractive industries frequently results from an incomplete accounting of the environmental and social costs of these industries. This incomplete accounting results from both insufficient understanding and public awareness of the ecological and social consequences of developing renewable and nonrenewable resources and from inadequate definition of property rights associated with ecological resources that are affected by development. Often the cumulative ecological and social impacts of resource extraction are ignored (34).

\section{Legacies and Thresholds}

Legacies constitute the memory of the system and the means for regenerating system function after disturbance or collapse. Most boreal forests, for example, are highly resilient to fire, insect outbreaks, and other natural disturbances, because the local flora is adapted to these disturbance cycles and requires periodic disturbance for maintenance of populations through time $(35,36)$. Management that seeks to control disturbance or replace natural disturbances with new ones such as forest harvest can, under some circumstances, reduce the regeneration potential and resilience of the system (37-39).

Other disturbances are novel. Pesticides accumulate dramatically in food chains because animals require an abundans of fat to survive in cold environments or to migrate long distances. e.g. fish and birds. Similarly, lichens and reindeer accumulate radionuclides, e.g. Chernobyl, Novaja Zemlja, belowground explosions in Eastern Russia. Strong bio-concentration causes persistent organic pollutants and radionuclides to be stronger stressors at high latitudes than elsewhere, threatening human health and the natural resilience of these systems.

In tundra the longevity of individual plants is often an important legacy that contributes to resilience. Some plants can survive for thousands of years through vegetation resprouting (clonal reproduction) (40), if they successfully survive critical bottlenecks in the life cycle such as disturbances (41).

Permatrost is a key physical property that shapes the resilience of high-latitude systems. It restricts plant access to mineral soils, prevents vertical drainage, and dictates the hydrologic regime that controls many ecosystem properties. There is an abrupt threshold for existence of permafrost at a mean annual temperature of about $0^{\circ} \mathrm{C}$. The large ecosystem consequences of this threshold render the system vulnerable to warming. The threshold is quite predictable, however, providing opportunities for innovation and planning. Other thresholds result from the nonlinear response of population viability to habitat loss, as observed in many species (42).

Traditional and local ecological knowledge and the institutions in which this knowledge is embedded are critical reservoirs of understanding about interactions between people and their environment and therefore a key source of resilience in northern systems. As the climate changes, however, traditional cues for predicting the environment no longer work. Several groups of arctic people have observed that the weather is now more variable, and the frequency of extreme weather events has increased. These interrelated changes effectively "strip arctic residents of their considerable knowledge. predictive ability, and self-confidence in making a living from their resources. This may ultimately leave them as strangers in their own land" (13) and increase their vulnerability to both climatic and social changes (43).

\section{Innovation and Learning}

Given the vulnerability that all regional systems exhibit to both surprises and predictable change, it is not surprising that systems often undergo radical change. At these times the capacity for innovation and learning is critical to long-term resilience and the sustainability of fundamental attributes of the system (17).

Adaptive management, in which resource management practices are modified based on learning from previous management efforts, provides a sound basis for learning from both successes and failures (21). This has always been an integral component of the interactions between indigenous people and the land, so it is not surprising that co-management efforts involving indigenous groups frequently have a strong adaptive component to management.

Resolution of the property rights of indigenous people has been a key test of their capacity for innovation and learning. These issues came to the fore in North America in the 1950s and 1960 s as Canada and the United States attempled to lay claim to the high arctic islands and to Alaskan petroleum resources. respectively. Resolution of these property rights led to a resurgence of pride in traditional values and a focus on management of the subsistence resources on which these communities depend. A variety of co-management institutions have evolved that integrate traditional and western approaches (44). In Russia, where the property rights of indigenous peoples remain unresolved, local people are often denied rights to fish. hunt and access pastureland, leading to continued erosion of cultural values. In Fennoscandia. the Saami are Europe's only officially recognized indigenous group. In northern areas, a small minority of Saami still practice traditional livelihoods. e.g., reindeer herding, within increasingly restrictive agricultural norms set out by the respective nations and in competition with other land uses (forestry, mining, hydropower. hunting. fishing. tourism), thus demonstrating astonishing persistence and resilience. Secure use rights have proven elusive, especially in Sweden where the courts have generally denied claims to indigenous rights, despite state recognition of these rights a century ago (45).

\section{Challenges for the Future}

Many of the current drivers of change in northern systems are projected to continue or intensify in the future. These include climatic warming, accumulation of pollutants, extraction of raw materials, penetration of western culture into indigenous communities, and an expansion of tourism. All of these expected changes originate primarily from pressures outside the arctic and boreal forest, so northern residents cannot readily reverse these trends. Instead, northern residents must be prepared to learn, cope, and adapt. The drivers of greatest change in the north are strikingly different than those in most other regions of the globe, where the strongest drivers are local in nature: population growth, industrial development, urbanization, and land-use change. We discuss how our understanding of the ingredients of resilience can be used to design strategies that maximize resilience and reduce the prospects for undesirable future change. 


\section{Anticipate Variability and Change}

The north is a land of pronounced variability, in which caribou herds and other animal populations routinely vary by more than an order of magnitude over time (46); extensive fires and forest pest outbreaks occur in one or a few years each century (47. 48): and economies boom and bust. Superimposed on this natural variability are directional trends in climate, economic globalization. national political and social change, and intermixing of indigenous and western cultures. Future plans must incorporate tlexibility in anticipation that these patterns and trends will likely continue. For example, rather than designing nature reserves as static refuges on a landscape that is frozen in place. We should anticipate that disturbances will occur and climate will change. This context requires that there be multiple refuges linked by corridors that provide opportunities for refugial populations to recolonize after disturbance and for migration to occur upward in elevation or northward along corridors in response to climatic warming (49). Even with optimal reserve design, we should expect increased invasion of exotic species and extinction of existing species if the environment continues to change. threatening even species that are currently widespread (9).

If we anticipate that reindeer and caribou herds will expand and collapse periodically, we must understand the factors that regulate population density after collapse. These controls may include harvest by people and other predators, migration from other herds. and cow/calf nutrition. Policies for management must be flexible enough to foster conditions for herd recovery at times of low population density. Similarly, most marine fish stocks exhibit high variability over decades to centuries, requiring policies that plan for reduced human harvest at times of searcity. At these times. when human harvest must be curtailed. it is important to minimize human vulnerability.

If tish are culturally important, how can this cultural thread be maintained? For example, the Cree Indians used as a cue the reduced fish catch per unit effort (CPUF) to switch to new fishing areas (12). Cultural practices safeguarded against exploitation of depleted stocks until they had recovered. Co-management involving local stakeholders and indigenous communities who are committed to the persistence of these stocks often fosters the long time horizon that is compatible with the time scale of these fluctuations. In some cases, periods of population decline are indicative of habitat deterioration, so the decline provides an opportunity for the habitat to recover to a level that can support larger populations over longer times. In the North Pacific salmon fishery, subsistence fishers are given priority over commercial and sport fishers at times of low abundance.

We expect that extractive industries in the north will continue to experience both good and bad times. depending on the state of the global economy. Continued economic dependence on these industries in the north virtually guarantees times of future conomic hardship (50). There are at least two strategies that could be adopted in planning for this eventuality: i) recognizing that this will oceur and planning contingencies to minimize the impacts on vulnerable portions of society during times of economic crisis; and/or ii) promoting economic diversity that reduces the dependence on extractive industries.

Alaska was unsuccessful in planning for future economic hardship at a time when oil revenues were abundant because of the failure to recognize factors governing institutional rigidity. During the period of wealth in the 1970s two institutional changes were legislated. One established a Permanent Fund, the interest of which was intended to fund state expenditures during and after the oil boom. The unanticipated decline in the stock market, combined with the inability of legislators to leave the principal intact, minimized the effectiveness of what originally appeared an innovative approach to managing economic variability. The second institutional change abolished individual taxation as a source of state revenue during the period of wealth and offered all citizens of the state a dividend from the interest of the Permanent Fund. When the state economy collapsed, individual citizens and their political representatives were unwilling to reduce the dividend or re-institute taxation. leaving social services even more dependent on revenue from extractive industries than before the discovery of oil. This case study demonstrates the importance of both institutional flexibility and unexpected surprises in governing vulnerability to economic fluctuations.

\section{Manage the Slow Variables and Critical Habitats}

An understanding of the slow variables, i.e. key process controls that degrade and recover slowly and critical habitats that govern long-term dynamics is key to the development of sound policies that manage for resilience (20). For example, soil organic matter content governs nutrient retention and the long-term productive potential of soils. Stream gravels and temperature, as mediated by forest canopy and sediment inputs to streams, govern the suitability of spawning habitat for wild salmon. The oral traditions and stories told by native elders are the "libraries" of traditional knowledge that ensure the integrity of indigenous cultures (51). Particularly at times of crisis. however, managers and the public tend to focus on the fast variables, such as insect outbreaks, collapse of fish stocks. or threats to an endangered species. These perceived crises might be either natural events that are difficult to mitigate or symptoms of longer-term dynamics that could have been prevented by managing for slow variables. Failure to manage the slow variables can lead to irreversible changes, such as the loss of a fishery or traditional ties to the land. with grave societal consequences.

In many cases there are critical habitats or institutions that exert a disproportionate impact on long-term dynamics and therefore warrant particular attention. For example, the number of caribou calves that reach three weeks of age-by which time they are relatively mobile and less vulnerable to predation-is critical to the long-term population dynamics (52) Industrial development that occurs in traditional calving areas often disturbs pregnant cows and attracts foxes. ravens. and other predators, exerting a disproportionate impact on early calf survival. Other critical habitats include spawning areas for wild salmon and old-growth forests in Scandinavia. which are critical reservoirs of biodiversity of predatory bcetles and other components of wood-decomposing food chains.

Institutions that foster ecological and cultural diversity retain the seeds for innovation on the landscape. These institutions are sometimes viewed as old-lashioned and inefficient in meeting short-term objectives, but can play key roles in revitalizing economies at times of rapid change (53).

\section{Plan for Expected and Unexpected Change}

Northern regions have an unusual advantage in planning for the future, because we can anticipate many of the important drivers of future change. We are virtually certain to see continued or increasing rates of climate warming, pressure from extractive industries, and mixing of western and indigenous cultures. Planning for a resilient future must occur in the context of these expected changes. For example, as climate warms and sea ice declines, marine mammats will likely decline in abundance, retreat northward with the sea-ice margin. move to 
less stable single-year ice. and/or be replaced by other fish and mammal populations that are less ice-dependent (16). Given the strong nutritional and cultural dependence of many coastal indigenous communities on hunting of marine mammals, future options to adapt to these changes might include changes in technology to allow travel to more distant or less stable ice environments and/or the exploration of alternative subsistence resources that sustain strong cultural ties to the land and sea.

Similarly, on land, it is virtually certain that continued climate warming will have significant impacts on the forest resource, due to both changes in disturbance regime and changes in growing conditions. These impacts will have profound economic impacts on communities that depend on this resource, and for those who live within its borders. It will also cause permafrost to thaw, altering hydrology and the stability of buildings, roads, pipelines, and other infrastructure. Surface vegetation also affects permafrost stability, so changes in disturbance could interact with climate warming to influence the future integrity of permafrost. Planning for the future should consider these interactions and their consequences for hydrology. ecological diversity, and the interactions of people with the landscape.

Climate warming will also interact with pressures for resource extraction. as northern oceans become more navigable, bringing northern oil and gas closer to major markets. Similarly, arctic fish stocks that are currently inaccessible may become commercially viable as sea ice retreats. Careful co-management of both renewable and nonrenewable resources could provide opportunities to enhance local economic benefits and ecological and societal resilience.

Changes that are now unanticipated or seem unimportant will also occur and are more difficult to plan for. However, the increased institutional flexibility required in planning for expected changes is also one of the most important prerequisites for responding to unanticipated changes. Major potential surprises that should be considered include the possible cooling in the North Atlantic Region if deep water formation is reduced, potential drying of the tundra to produce unproductive arid treeless areas (rather than new forest areas) similar to the tundra steppes of the Pleistocene and early Holocene, and paludification (waterlogging) causing tree death in areas of forest where permafrost may thaw and the climate becomes more oceanic (9).

\section{Foster Learning and Innovation}

Given the strong drivers of change operating in the north, conditions that foster learning and innovation are critical for increasing the future capacity for resilience. This capacity building must occur at several levels, including the research community, northern residents and governments, and the global community.

Enhancing the capacity for resilience requires a new kind of science that is more interdisciplinary and speculative in order 10 consider and evaluate options that might not occur to ecologists. economists. or anthropologists acting in isolation. It must recognize the connections that occur across temporal and spatial scales. for example the long-term consequences of short-term fire-prevention policies (54) or the consequences for rivers and estuaries of upstream agricultural development (55). The development of "what if" scenarios and gaming to explore the logical consequences of different possible futures or different assumptions about how people interact with ecological systems are constructive approaches to exploring system vulnerability and resilience $(56,57)$.

Engaging local residents, managers, businesses, and policy makers in the design and implementation of this research increases the likelihood that practical alternatives will be considered and that the results will be applied $(58,59)$. Anticipatory strategies must be developed that mitigate or adapt to expected changes, for example through changes in protective systems, pathways to initiate policy change, and information availability to residents and businesses. For example, climate warming increases opportunities for high-latitude agriculture. which could reduce the food dependence of northern people on supplies from the south. Similarly, increased ecotourism may increase the incentives for environmental protection by extractive industries and regulatory agencies. These and other changes will likely attract people from the south seeking $\mathrm{cm}$ ployment. Although these migrants will compete with local people for jobs, they also bring a broader range of experiences and an additional source of innovation.

Increased communication among arctic nations by researchers, indigenous peoples, urban dwellers, resource managers, and policy makers provides an important source of learning that could lead to innovation. Most northern countries have been and will continue to be impacted by the same drivers: climate warming, extractive industries, urbanization, and mixing of western and indigenous cultures. However. this global experiment has been replicated in quite distinct cultural. economic, and political contexts, resulting in a diversity of oulcomes for a wide variety of issues, including resource management. environmental protection, designation of property rights, and institutional change $(60)$.

Finally, northern researchers and residents have an important responsibility for conveying to the world at large the surious impacts that anthropogenic climate change is already having in the north. Northern regions are the canary in the mineshalt of global change - the first place where anthropogenically induced climate warming has clear effects. Only by convincing world leaders that these effects are real and have serious societal consequences is it likely that global actions will be taken to mitigate these changes. The eight aretic nations together account for $40 \%$ of the global emissions of $\mathrm{CO}_{2}$, the largest anthropogenic contributor to climate warming. Establishing an effective communication between policy makers in these nations and northern residents, scientists, and businesses is ono of the most promising avenues available to minimize or reverse current climatic trends.

\section{References and Notes}

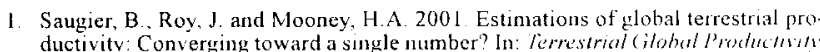

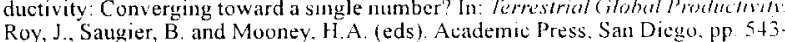
Roy

2. Mann, M.E., Bradley, R.S and Hughes. M.K. 1999. Northern hemisphere temperatures during the past millennium: Inferences, uncertainties and limitation (jeophys. Res. I.ett 26, 759-762

3. Ramaswamy, $V$ et al 2001 . Radiative forcing of climate change. ln: (1/mmih Change 2001: The Scientific Barsts. Houghton. J.T. Ding. Y.. Griggs, D.J. Nogues. $M$. van der Linden, P.J., Dai, X., Maskell, K. and Johnson. C.A (eds). Cambridge University Press. Cambridge, pp. 349-416

4. Chapin, F. S , III. Eugster, W., McFadden. J P. Lynch. A. H. and Waiker. D. A. 2000 Summer differences among arctic ecosystems in regional climate forcing. $J / \%$ mate $13,2002-2010$

5. Callaghan, T.V., Werkman, B.R. and Crawford, R.M.N 2002. The tundra-tisig

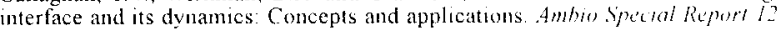
6-14

6. Overpeck, J. et al 1997. Arctic en ironmental change of the last four centuries Siclence $278,125 \mathrm{I}-1256$

7. McGuire, A.D. et al 1997. Equilibrium responses of global net primary produc tion and carbon storage to doubled atmospheric carbon dioxide. Sellsitivity io

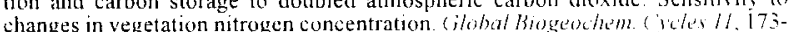
189

8. Shaver GR Billings, WD Chapin, FS [II Ciblin AF Nadelhoffer $k$ ] Oechel WC and Rastetter E B 1992 Global change and the carbon balance of arctic ecosystems Rirsience ol $415-435$.

9 Calla Callo

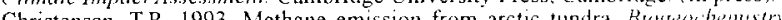


21.117 .139

11. Peterson. B.J. Holmes, R.M. MlcClelland. JW. Vörösmarty, C.J., Lammers, R.B. Shiklomanos, A 1, Shiklomanov, I.A. and Rahmstorf, S. 2002. lacreasing arctic river discharge to the Arctic Ocean. Airtence 298, 2171-2173.

12. Berkes. F. 1995. Indigenous knowledge and resource management systens: a natwe Canadian case study from James Bay. In. Property Rights in a fiocal and

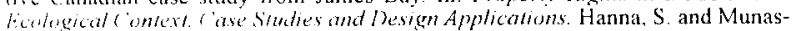
inghe. $M$ (eds) Beijer Lutenational Institute of Ecological Economics and the Wurds Bank, Washington, pp $99-109$

13. Berkes. F. 2002. Epilogue: Aaking sense of arctic environmental change? In: The licurh Is lastur Nou Krupuit 1 and Jolly, D. (eds). Arctic Research Consortiun of the United States. Fairbanks, Alaska. pp. 335-349

14. Sturm. M. Racine. C. and Tape, K. 2001 . Increasing shrub abundance in the Arctic Vuluer $+1 / 546-547$

15 Forbes. B C Ebersole, J.J and Strandbery. B. 2001. Anthropogenic disturbance and patch dy namics in circunpolar arctic ecosystems. ('onserv: Biol. 15, 954969

16. Krupnik, 1 2002. Watching ice and weather our way: Some lessons from Yupik obsersations of sea ice and weather on St. Lawrence island, Alaska. lin: The Farth Kruptik, and Joily D (eds). Arctic Research Consortiun of the United States, Furbarks p 156-197.

17. Berkes. F. Colding. J. and Folke, C. (eds) 2003. Navigaing Social-ticological Sistems: Buldem Resilience for ('omplexify and ('hange Cambridge University Press, Cambridge, 393 pp

18. Holliny. CS. 1986. Resilience of ecosystems: Local surprise and global change In Sistamoble Derelopmemt and the Biosphere. Clark, W.C. and Munn, R.E leds). Cambridge Universitv Press, Cambridge, pp. 292-317.

19. Folke, C et al. 2002. Resilience and sustainable development: Building adaptive capacity in a world of transformations. IC SU. Tech. Report 3, 1-74

20. Carpenter, S.R. and Turner, M.G. 2000 . Hares and tortoises: Interactions of fast and slow variables in ecosystems. ficosystem. 3, 495-497.

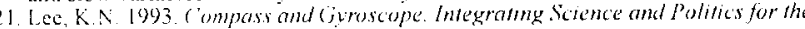
Fimrojment lsland Press, Washington, $243 \mathrm{pp}$

22. Chapin. F.S., Ifl and Danell. K. 2001. Boreal forest. In: Global Blodversty' an a

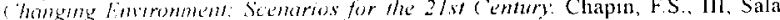
Ot: and Huber-Sannwald. E (eds) Springer-Verlag. New York, pp. $101-120$

2: Chun. FS III Catlauhan TV Bergeron, Y. Fukuda M Johustone, J.F Juday, $G$ and Zimov, S 2004 Global change and the boreal forest: Thresholds, shifting states or gradual change? A tmbo 33, 36/-36,5.

24. States or gradial change Ambo 33 . Mr

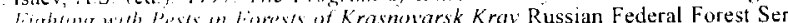
(1)

25 Apps, M.J and Kurtz, W. A. 1993. The Role of Canadian Forests in the Global

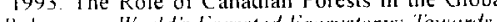
Carbon Balance. In: (arbon Balamce in Worlds orested tecosysems. Johal Ass

20. Stevent $\mathrm{MG}$ and Webb, J. 2003. Just another stakeholder? First Nations and stevente sustainable forest managentent in Cata P.J. (ed.). NRC Research Press, Ottawa Manageme

27 Wh 65-112. G. Forbes. B.C. Niemelä, J. and Chapin, F.S., III 2004. Bringing feedback and resilience of high-latitude ecosystems into the corporate boardroom. $A m-$ bus $33.372-377$

28. Chapin. FS. III 1983. Direct and indirect effects of temperature on arctic plants. Pelur Rol 2. 47-52

29. Billings, WD 1973 . Arctic and alpine vegctation: Similarities, differences, and susceptibility to disturbance. Bhescience 23,697-704

30. Goulden, ML et al 1998. Sensitivity of boreal forest carbon balance to warming Sirnce $279,214-217$

1. Kurz. WA and Apps. N.J. 1999. A 70-year retrospective analysis of carbon fluxe in the Canadian forest sector. I:col. Appl 9, 526-547.

3 Shidenko $A$ and Vilsson. S. 2003. A synthesis of the impact of Russian forest on the ulobal carbon budget for 1961-1998. Fel/us $55 \mathrm{~B}, 391-415$.

3 Amire 13 D ef al 2001 . Direct carbon emissions from Canadian forest fires, 195 - 199\% (im J lor Res. $31,512-525$.

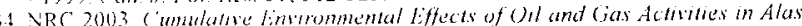
has Norh sitome National Acidemies Press, Washington, 288 pp

35 Chapin, F. . III. Callaghan, T.V. Bergeron, Y . Fukuda, M.. Johnstone, J.F., Juday, $G$ and 2004 ing statis or gradual change" $A m b i o 33,36 /-365$
36. Angelstam, P. and Kuuluvainen, T. 2004. Boreal forest disturbance regunes, sucessional dynamics and landscape structures - a European perspective. / Kcol. Bull 51. (In press)

37. Bengtsson. J., Angelstam, P., Elmagisi. T. Emanuelsson, U, Folke, C. Ihise, M! Moberg, F and Nystrom. M. 2003 Reserves, resilience, and dyamu landscapes Ambio 32, 389-390

38. Bergeron. Y. Flannigan. M. Gauthier. S. Leduc A and Lefort. P. 2004 Patst, current and future fire frequency in the circumpolar boreal forest lmplications to sustainable forest management Ambio 33. 356-360.

39. Crépin, A.-S. 2003. Multiple species boreal forests - what Faustmann missed fin virun. Resour. Licon. 26, 625-646

40. Jónsdóttir, I.S., Augner, M., Fagerström, T., Persson, H. and Stenstrom, A. 2000 Genet age in marginal populations of two clonal ('urex species in the Siberian Arctic. Ficogrophr $43,402-412$

41. Callaghan. T.V Jonasson, S and Brooker, R. 1997. Aretic clonal plants and global change. In: The Ecology and firolution of ('lonul Plants, de Kroon, H. and Groenendael I (eds). Bachuys Publishers, Leiden, pp. 381-403.

2. Fahrig, L. 2002. Effect of habitat fragmentation on the extinction threshuld. A synthesis. licol. Appl. 12, 346-353.

43 Norton, D W 2002 Coastal sea ice watch: Private confessions of a convert to 11 digenous knowledge. In: The tarth Is Farter Now Indigentus observations of digenous knowledge. The Kropnik l and Jolly D (eds) Arctic Reseatch Arche Envommental hange. Krupnik. 1 and Joly. D $27-155$

44 Kofinas. G. P and Conmunities of Aklavik and Old Crow. 2002 Communty contributions to ecological monitoring: Knowledge co-production in the U. S. - Canada tributions to ecological montoring: Knowledge co-production of the U.S. - anad artic borderlands. The Larme.

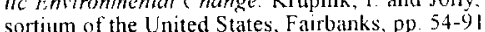

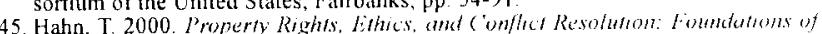
the Sami Economy in Sivecten PhD Dissertation, Swedish University of Auricultural Sciences, Sweden, pp. 1-225.

46. Krebs, C.J., Boutin. S. and Boonstra. R., Eds 2001 . Fcosystem Im namicr of the Boreal foress: The Kluane Provect. Oxford University Press, Oxfurd, $544 \mathrm{pp}$

7. Kurz W A Apps. MJ Beukema. SJ and Lekstum T 1995 $20^{\text {th }}$ century carloun budget of Canadian forests. Tellhos $+7 \mathrm{~B}, 170-177$

48. Kasischke, E. S. Williams, D. and Barry, D. 2002. Analysis of the patterus of large fires in the boreal forest region of Alaska. Int. J. Wildind fire /I. 131.144

49 Elmqvist, T. Berkes, F. Angelstam, P. Crepin, A.-S and Viemeli, I 2004 The dynamics of ecosystems, biodiversity management and social institutions at high northern latutudes. Ambio 33, 350-355

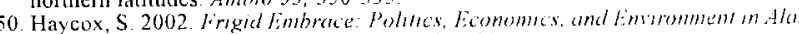
ka Oregon State University Press, Corvallis, $180 \mathrm{pp}$

51. Cruikshank, J 1998 The Socual Life of Sortes. Norrative and Knontedge th the Yakon Terrifur. University of Nebraska Press, Lincoln, $211 \mathrm{pp}$

52. Griffith B et al 2002 The Porcupine caribou herd. U.S Geological Survey, Biological Resources Division. Tech. Report Biological Scrence Repont (STCS RR/). $2002-0001$

53. Carlsson. L Augelstam, P and Lazdinus, M. 2004 Institutional franeworks for sustainability? A comparative studv of Russia and Latvia. Ambo 3.3. 366-377)

4 Chapin. FS III Rupp TS Starfield A.M. DeWilde, L.., Zavaleta, E.S. Freseo. $\mathrm{N}$ and McGuire A D 2003. Planning for resilience: Modeling change in humiut$\mathrm{N}$. and McGuise, $A$.D. 2003. Planning forest from fecol knitum. $/ .255-261$

5 . Carpere $S . R$.

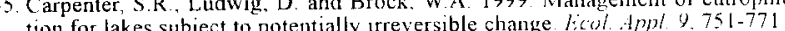
56. Carpenter, S.R., Brock. W.A. and Ludwig, D. 2002. Collapse. learning, and reCapen newal In I anarch: Understandm.

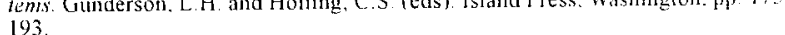

57. Peterson. G.D. Cumming, G.S. and Carpenter, S.R. 2003. Scenario pl

tool for conservation an an uncertain world (anteren. Biwl. /7. 358-366

58. Ostrom, E. 1990. (jowernmy the (ommons The bioluhen of inst

lectwe Actom Cambridge University Press, Cambridge, $280 \mathrm{pp}$.

59. Angelstam, P., Lazdinis, M. Mikusinski, G.. Roberge, J -M.. Olsson, J., Anberg.
$W$. and Ostman, A 2003 . Two-dimensional gap analysis: Improving strategic and W. and Ostman, A 2003 . Two-dimensional gap analysis: Improving stratequic and tactic conservation planning and biodiversity policy implementation. $4 m b w$ $526-533$

60. Forbes, B. Carlsson. L. Fresco, N. Juday. G. Shvedenko. A. Zimsos. S.. Danell. $K$. and Apps. M. 2004. Geographic variations in anthropogenc drivers that influence the vulnerability and resilience of high-latitude nations. A thbo $3.3,5-3 i 2$

\section{Corresponding author: \\ F. Stuart Chapin, III, Institute of Arctic Biology, University of Alaska, Fairbanks AK 99775, USA. \\ terry.chapin@uat.edu}

